\title{
Two-step Recrystallization of Water in Concentrated Aqueous Solution of Poly(ethylene glycol)
}

\author{
Makoto Gemmei-Ide,* Tetsuya Motonaga, Ryosuke Kasai and Hiromi Kitano* \\ Department of Environmental Applied Chemistry, Graduate School of Science and Engineering, University of Toyama, 3190 \\ Gofuku, Toyama, Toyama 930-8555, Japan.
}

(M.G.-I.) E-mail: ide@eng.u-toyama.ac.jp; Tel: +81-76-445-6870; Fax: +81-76-445-6703.

(H.K.) E-mail: kitano@eng.u-toyama.ac.jp; Tel: +81-76-445-6868; Fax: +81-76-445-6703.

\begin{abstract}
Crystallization behavior of water in a concentrated aqueous solution of poly(ethylene glycol) (PEG) with a water content of $37.5 w t \%$ was investigated by temperature variable mid-infrared (mid-IR) spectroscopy in a temperature range of $298-170 \mathrm{~K}$. The mid-IR spectrum of water at $298 \mathrm{~K}$ showed that a large water cluster was not formed and that most of the water molecules were associated with the PEG chain. Ice formation, however, occurred as found in previous studies by differential scanning calorimetory. Ice formations were grouped into three types: crystallization at $231 \mathrm{~K}$ during cooling, that at $198 \mathrm{~K}$ during heating, and that at $210 \mathrm{~K}$ during heating. The latter two were just recrystallization. These ice formations were the direct transition from hydration species to ice without condensation, regardless of crystallization or recrystallization. This means that the recrystallized water in the present system was not generated from low-density amorphous solid water. At a low cooling rate, nearly complete crystallization at $231 \mathrm{~K}$ during cooling and no recrystallization were observed. At a high cooling rate, no crystallization and two-step recrystallization at $198 \mathrm{~K}$ and $210 \mathrm{~K}$ were observed. The former and latter recrystallizations were found to be generated from water associated with helical and random PEG chains, respectively. The results also suggested that the latter needed motion of PEG chains, whereas the former did not. These results indicate that recrystallizable water does not have a single specific water structure.
\end{abstract}

Key Words: Diffusion, Glass transition, Mid-infrared spectroscopy, Water-polymer association.

\section{Introduction}

The origin of non-biofouling property of synthetic polymers has been widely discussed. The property is known to depend on charge, wettability, free energy, roughness, and stiffness of the polymer surface, but a universal explanation for the origin has not yet been found out. ${ }^{1-4}$ Synthetic polymers have many variations in their chemical compositions, but water molecules as the universal solvent in biological systems have a universal chemical composition, $\mathrm{H}-\mathrm{O}-\mathrm{H}$. Before contact between polymers and biological components, water molecules should exist on both surfaces as hydration layers. When contact occurs, the hydration layer should be removed: water is expected to play one of the most important roles in the contact event. ${ }^{5-7}$ From such a point of view, on the basis of physicochemical properties of water in polymer-water systems, many studies have been carried out.

Poly(ethylene glycol) (PEG) is one of the most well-known synthetic non-biofouling polymers. Its excellent properties have been shown by many studies. ${ }^{8}$ Many researchers have investigated PEG-water systems, and the existence of water with a unique thermal behavior, that is, recrystallized water, has been found. ${ }^{9-15}$ Recrystallization of water is defined as ice formation below $273 \mathrm{~K}$ during heating. On the basis of differential scanning calorimetry (DSC), recrystallization of water in PEG-water systems has been reported to occur at $220 \mathrm{~K}$ and with a water content range of $10-95 w t \% .{ }^{10,13}$ About ten years ago, there were a few studies that discuss a relationship between the non-biofouling property of polymers and recrystallization of water in their matrices. In the case of PEG, it has been hypothesized that the origin of the non-biofouling property is an interfacial water layer stabilized by hydrogen $(\mathrm{H})$-bonding between water molecules and the PEG chain with a $7 / 2$ helical conformation at the physiological temperature $(T){ }^{16-25}$

However, much interest has recently been shown in the relationship between the non-biofouling property and recrystallization of water due to the finding by DSC of recrystallization of water in poly(2-methoxyethyl acrylate) $(\mathrm{PMEA})^{26,27}$ having excellent blood compatibility. In fact, DSC analysis revealed the existence of recrystallized water in some non-biofouling polymers such as poly $\left(N\right.$-vinyl pyrrolidone) $(\mathrm{PVP}),{ }^{28}$ polysaccharides, ${ }^{29-31}$ and 
poly(2-methacryloyloxyethyl phosphorylcholine) (PMPC), ${ }^{32,33}$ although there was difference between water-soluble polymers (PEG, PVP, polysaccharides, and PMPC) and non-water soluble polymer (PMEA). The recrystallized water was hypothesized to be the interfacial multi-layered water molecules having a specific H-bonding structure that is recrystallizable and prevents biofouling at the physiological $T .{ }^{34}$

The two hypotheses are the same in that the hydration layer formed by some specific H-bonding prevents biofouling. However, if the recrystallized water and the stabilized interfacial water layer are the same, it is difficult to accept that the water content range in which recrystallized water was observed was relatively limited except for PEG: $10-95 w t \%$ for PEG, $33-47 w t \%$ for PMPC, 30-71 wt \% for polysaccharides, and $48 w t \%$ for PVP. ${ }^{28,32}$ This doubt is naturally generated if the two hypotheses are consistent. Furthermore, according to the latter hypothesis, recrystallized water is generated from the glassy water formed by vitrification of the multi-layered water molecules with a specific H-bonding structure at the physiological $T$. However, taking into account the number of water molecules per unit of polymer $\left(\mathrm{N}_{\text {water }}\right)$, it is doubtful whether the latter hypothesis can explain the recrystallization of water in a highly concentrated PEG solution. The $\mathrm{N}_{\text {water }}$ range in which recrystallized water is observed is $0.3-46.4$ for PEG. ${ }^{10,13}$ In addition, recrystallized water has been also found in other polymers which are not biocompatible. ${ }^{35,36}$

In this study, the recrystallization of water in a concentrated aqueous solution of PEG was investigated by temperature variable mid-infrared (mid-IR) spectroscopy. DSC analysis is a powerful tool for investigating changes in a state such as freezing, melting, vitrification, and devitrification on the basis of the heat flux. However, on the basis of its principle, it is not possible to observe in situ the state of matters, and several changes with heat flux cannot be investigated separately if they occur simultaneously. In the case of PEG-water systems, recrystallization of water and crystallization of PEG are considered to occur simultaneously. ${ }^{10,13}$ This means that these two events cannot be distinguished by DSC. On the other hand, mid-IR spectroscopy probes molecular vibrations being unique to certain chemical bonds, which allows observation in situ of the state of matters and investigation of the states of PEG and water separately. The purpose of this study was to clarify how water molecules recrystallize even in a highly concentrated aqueous solution of PEG in which most of the water molecules are associated with PEG chains.

\section{Experiments}

Poly(ethylene glycol) dimethyl ether (PEG) (Aldrich) was purified by precipitation in ethanol-ether. The weight-average and number-average molecular weights of PEG were 2063 and 2034, respectively. The quality of water used in all experiments was Milli-Q grade (resistivity $>18.2 \mathrm{M} \Omega \cdot \mathrm{cm}$ ). The PEG film was prepared from its chloroform solution on a sapphire substrate of $13 \mathrm{~mm}$ in diameter. The thickness of the film was determined from the diffraction pattern of visible light. Films with thicknesses of $\sim 0.5$ and $\sim 10 \mu \mathrm{m}$ were prepared for mid-IR measurements of the $\mathrm{CH}$ stretching region of $\mathrm{PEG}$ and the $\mathrm{OH}$ stretching region of water in the system. The film was hydrated by exposing it to humid air with relative humidity of $61 \%$ or $88 \%$ at $310 \mathrm{~K}$ for 10 days. Water content $\left(\mathrm{W}_{\mathrm{C}}\right)$ was gravimetrically determined to be 1.42 and $37.5 w t \%$, respectively. The latter sample was in the solution state. After hydrating, the sample was covered with another sapphire substrate and set in a home-made sample holder and was then tightly sealed with indium. When the sample with $\mathrm{W}_{\mathrm{C}}$ of $37.5 \mathrm{wt} \%$ was set in the holder, some of it was spilled out, and the spectral intensities of water in the two samples are therefore not comparable.

Mid-IR spectra of the sample were recorded on a Spectrum One NTS (Perkin-Elmer) with a resolution of $4 \mathrm{~cm}^{-1}$ and a scanning time of $20 \mathrm{sec}$. The sample with $\mathrm{W}_{\mathrm{C}}$ of $1.42 \mathrm{wt} \%$ and the dried sample were measured at $298 \mathrm{~K}$. The spectrum of water in the sample with $\mathrm{W}_{\mathrm{C}}$ of $1.42 w t \%$ was obtained by subtraction between the spectra of the hydrated and dried films. The sample with $\mathrm{W}_{\mathrm{C}}$ of $37.5 \mathrm{wt} \%$ was measured in a $T$ range of $298-170 \mathrm{~K}$. Cooling rates were $1.0,1.9,2.9$ and 4.9 $\mathrm{K} \cdot \mathrm{min}^{-1}$ and heating rate was $1.0 \mathrm{~K} \cdot \mathrm{min}^{-1}$. The temperature of the sample was controlled by an Optistate-DN cryostat (Oxford) connected to a model ITC601 $T$ controller. In the case of the sample with $\mathrm{W}_{\mathrm{C}}$ of $37.5 \mathrm{wt} \%$, subtraction was not carried out because the spectral contribution of PEG to the $\mathrm{OH}$ stretching region was negligibly small.

\section{Results}

Spectra at 298 K. Mid-IR spectra of water in PEG-water systems are shown in Figure 1. The spectral profiles of water in PEG-water systems were different from the spectrum of pure water. Water molecules in solid PEG ( $\mathrm{W}_{\mathrm{C}}$ of $\left.1.42 w t \%\right)$ were reported to be in monomeric or dimeric states associated with the oxygen atoms of PEG chains via H-bonding and to be localized in the amorphous region of PEG. ${ }^{37-39}$ As is well known, PEG is a crystalline polymer and a PEG chain in the crystalline region has a 7/2 helical conformation: the band at $2885 \mathrm{~cm}^{-1}$ has been assigned to symmetric $\mathrm{CH}$-stretching of the helical PEG. ${ }^{40,41}$

In the case of $\mathrm{W}_{\mathrm{C}}$ of $37.5 \mathrm{wt} \%$, although this sample was in the solution state, the spectrum of water in the system was similar to that for $\mathrm{W}_{\mathrm{C}}$ of $1.42 \mathrm{wt} \%$ rather than that of pure water. The spectral difference was that the relative intensity of absorbance at $3420 \mathrm{~cm}^{-1}$ to that at $3270 \mathrm{~cm}^{-1}$ was much larger than that for $\mathrm{W}_{\mathrm{C}}$ of $1.42 \mathrm{wt} \%$. In this frequency region, liquid water in its spectrum has a shoulder at $3250 \mathrm{~cm}^{-1}$ and a broad peak at $3410 \mathrm{~cm}^{-1}$. Therefore, the possibility of the existence of large water cluster cannot be denied. However, considering that the number of hydrating water molecules per PEG unit was reported to be $2-6^{42-47}$ and that the average number of water molecules per PEG unit in the present system was 1.47 , most of the water molecules are thought to be associated with the PEG chain. 
The spectrum in the $\mathrm{CH}$ stretching region (right in Figure 1) showed a drastic decrease in helical PEG chains, indicating that the water molecules destroyed (molted) the crystalline region of PEG and were then associated with $O$ atoms of the PEG chains. However, the characteristic peak of the helical PEG chain clearly remained, indicating that a part of the helical PEG was maintained.

\section{Spectral Changes by Temperature Perturbation.}

a. Pure Water. $T$ dependence of the mid-IR spectrum of pure water is shown in Figure 2. During cooling, the spectra with a very broad feature above $251 \mathrm{~K}$ changed to spectra with a sharp band at $3250 \mathrm{~cm}^{-1}$, which was a characteristic peak of ice $I_{\mathrm{h}}$ (left panel). During heating, the sharp band returned to the broad one above $273 \mathrm{~K}$ (spectra not shown). In the plot of absorbance at $3250 \mathrm{~cm}^{-1}$ (A3250) vs. $T$ (right panel), discontinuous changes in A3250 were observed at $251 \mathrm{~K}$ and $273 \mathrm{~K}$ during cooling and heating, respectively. These changes are freezing and melting, respectively. The lower freezing $T$ than the thermodynamic melting $T$ of water, $273 \mathrm{~K},{ }^{48}$ is merely supercooling of water. The spectrum of liquid water is very different from that of ice and therefore the state of water (liquid water or ice) can be determined on the basis of them. In addition, freezing and melting points can be determined from the discontinuous change in A3250, too.

b. PEG Solution ( $\mathbf{W}_{\mathbf{C}}$ of 37.5 wt\%, Figures 3-5). Figures 3 and 4 show $T$ dependence of the spectra at cooling rates of 1.0 and $4.9 \mathrm{~K} \cdot \mathrm{min}^{-1}$, respectively. The spectra at cooling rates of 1.9 and $2.9 \mathrm{~K} \cdot \mathrm{min}^{-1}$ are given in Supporting Information. Figure 5 shows $T$ dependence of A3250 and A2885 at various cooling rates.

Cooling process. Regardless of the cooling rate, the spectral changes were the same down to $231 \mathrm{~K}$. The absorbance of water molecules in the higher and lower frequency regions decreased and increased, respectively, indicating that the associated water molecules increased. As shown in panel c of each of the figures, however, the spectral dissimilarity of water in the present system to that of low density amorphous solid water (LDA, dotted spectrum) ${ }^{49,50}$ at $233 \mathrm{~K}$ indicated that a large water cluster is not formed. On the other hand, the spectra of the CH-stretching of PEG showed an increase in A2885 (Figure 5), indicating an increase in helical PEG chains. ${ }^{40,41}$ These changes did not depend on the cooling rate down to 231 $\mathrm{K}$, but they strongly depended on the cooling rate below $231 \mathrm{~K}$.

At a low cooling rate of $1.0 \mathrm{~K} \cdot \mathrm{min}^{-1}$, ice-like spectra (Figure 3) and a steep increase in A3250 below 231 K (Figure 5) were observed, indicating ice formation. As shown in panel $\mathrm{c}$ in Figure 3, the similarity of the spectrum at $170 \mathrm{~K}$ to that of ice (dotted line) suggests freezing of most of the water molecules in the system. On the other hand, $T$ dependence of A2885 (Figure 5) shows a steep increase in helical PEG chains at the same $T$ as that for ice formation, $231 \mathrm{~K}$, where the sample suddenly turned opaque. These changes suggest that crystallization of PEG occurred with a phase separation. The spectrum of CH-stretching at $170 \mathrm{~K}$ (panel c) is superposed on that of the dried PEG (dotted line).

At a high cooling rate of $4.9 \mathrm{~K} \cdot \mathrm{min}^{-1}$, down to the lowest $T$ of $170 \mathrm{~K}$, the spectral change of water was continuous (Figure 4) and the change in A3250 was also continuous (Figure 5). No ice-like spectra were obtained throughout the $T$ range. Moreover, changes of the spectra of the CH-stretching of PEG (Figure 4) and the value of A2885 (Figure 5) were no longer observed below $240 \mathrm{~K}$, indicating no change in the helicity of PEG in this $T$ range. The sample remained transparent down to $170 \mathrm{~K}$.

At intermediate cooling rates of 1.9 and $2.9 \mathrm{~K} \cdot \mathrm{min}^{-1}$, crystallization of both water and PEG was also observed below $231 \mathrm{~K}$. However, $T$ dependence of A3250 and that of A2885 (Figure 5) indicate little ice formation and crystallization of PEG compared to those at a cooling rate of $1.0 \mathrm{~K} \cdot \mathrm{min}^{-1}$. It should be noted that the temperature at which the change in A3250 becomes a straight line is slightly lower than that for A2885: T's for A3250 and A2885 are $200 \mathrm{~K}$ and $210 \mathrm{~K}$, respectively.

Heating process. Up to $198 \mathrm{~K}$, the spectra were traced back to those during cooling. The spectral changes above 198 $\mathrm{K}$ differed depending on the cooling rate. In the case of the sample cooled at $1.0 \mathrm{~K} \cdot \mathrm{min}^{-1}$ (Figure 3 ), the ice-like spectrum monotonously decreased in the absorption intensity up to $255 \mathrm{~K}$ and disappeared above $260 \mathrm{~K}$. A gradual decrease in A3250 up to $255 \mathrm{~K}$ and a steep decrease at $260 \mathrm{~K}$ correspond to the spectral changes (Figure 5). These changes indicate the reduction of ice at $255-260 \mathrm{~K}$. The reduction of ice is considered to be the direct change from ice to hydration species because liquid-like spectra were not obtained above $260 \mathrm{~K}$. The value of A2885 did not change up to $255 \mathrm{~K}$, indicating no change in the amount of crystalline PEG. In the $T$ range of $255-262 \mathrm{~K}$, the value of A2885 steeply decreased together with decrease in A3250. This indicates that the monomeric water dissociated from ice penetrates into the crystalline PEG and melts it. In this $T$ range, the sample became transparent again.

In the case of the sample cooled at $4.9 \mathrm{~K} \cdot \mathrm{min}^{-1}$, simultaneous increases in A3250 and A2885 occurred at $198 \mathrm{~K}$ (Figure 5). The spectral similarities between pure ice/dried PEG (dotted lines) and the present system at $210 \mathrm{~K}$ (Figure 4 ) show the formation of ice and increase in helical PEG chains. The ice formation observed here is just recrystallization of water, and on the other hand, the small increase in helical PEG chains might be crystallization of PEG with phase separation. Recrystallization of water (increase in A3250) and crystallization of PEG (increase in A2885) ceased at $210 \mathrm{~K}$, and with further warming, further increases were observed up to $220 \mathrm{~K}$ (Figure 5). As shown in panel c, the spectra for ice formed in the system and for the $\mathrm{CH}$-stretching of PEG at $225 \mathrm{~K}$ are similar to those of pure ice and dried PEG, respectively, more than those at $210 \mathrm{~K}$. In the $T$ range of $198-220 \mathrm{~K}$, the sample became opaque. Above $220 \mathrm{~K}$, the changes were the same as those of the sample cooled at $1.0 \mathrm{~K} \cdot \mathrm{min}^{-1}$. It should be noted here that two-step recrystallization of water at $198 \mathrm{~K}$ and $210 \mathrm{~K}$ occurred. Furthermore, the ratio of increase in A3250 to increase in A2885 in the first step was much larger than that in the second step. 
Two-step recrystallization of water was also observed at intermediate cooling rates of 1.9 and $2.9 \mathrm{~K} \cdot \mathrm{min}^{-1}$ (Figure 5 ). At the cooling rate of $2.9 \mathrm{~K} \cdot \mathrm{min}^{-1}$, two-step crystallization of PEG accompanied by recrystallization of water was observed, but at $1.9 \mathrm{~K} \cdot \mathrm{min}^{-1}$, crystallization of PEG was observed only at $210 \mathrm{~K}$ (Figure 5). Above $220 \mathrm{~K}$, the changes were the same as those of samples cooled at 1.0 and $4.9 \mathrm{~K} \cdot \mathrm{min}^{-1}$.

\section{Discussion}

Crystallization of water is grouped into three types: crystallization (1) below $231 \mathrm{~K}$ during cooling, (2) at $198 \mathrm{~K}$ during heating, and (3) at $210 \mathrm{~K}$ during heating. The latter two cases are just recrystallization of water. First, crystallization during cooling is discussed. Crystallization of water increased with a decrease in the cooling rate (Figure 5), indicating that crystallization in the present system is controlled by diffusion of water molecules. This is because ice growth in such a wide $T$ range of $30 \mathrm{~K}$ at intermediate cooling rates is not expected (Figure 5) if this crystallization occurred mainly by the rearrangement of water molecules. The distribution of crystallization $T$ of water in bulk has been reported to be no more than $5 \mathrm{~K}^{51-54}$ No liquid-like and LDA-like spectra in the entire $T$ range (Figures 3 and 4) also support the above speculation and indicate that crystallization in the present system is direct transition from the hydration species to ice.

Such a phenomenon has also been observed in the case of poly(2-methoxyethyl acrylate) (PMEA). ${ }^{55}$ The difference between PMEA and the present case is that the crystallization of water was accompanied by crystallization of a polymer (PEG). The reason why the increase in helical PEG chains (increase in A2885) down to $230 \mathrm{~K}$ was not considered to be crystallization is that a single helical PEG chain is allowed to be in the hydration state. This is consistent with the fact that the $7 / 2$ helical conformation observed at $298 \mathrm{~K}$ (Figure 1) does not mean the existence of crystalline PEG with phase separation. Phase separation (crystallization of PEG), on the other hand, should be required for the change from the situation in which the large association of water is inhibited physically (spatially) by the polymer chain to the situation in which ice as the large association of water molecules is formed.

Nearly complete crystallization of water and no crystallization was observed at the cooling rates of 1.0 and $4.9 \mathrm{~K} \cdot \mathrm{min}^{-1}$, respectively. The latter case indicates that all of the water molecules in the system were in a glassy state. This, however, does not mean the formation of LDA because LDA-like spectra were not observed at any $T$ (Figure 4). This glassy state should be achieved by water-PEG association. On the other hand, in the case of the samples cooled at intermediate rates, ice, crystalline PEG, and glassy domains (water-PEG association) coexisted at the lowest $T$. This is supported by the fact that the two spectra in the $\mathrm{OH}$ stretching region at $170 \mathrm{~K}$ (Supporting Information) can be reconstructed by the spectra of pure ice (Figure 2) and the PEG aqueous solution cooled at $4.9 \mathrm{~K} \cdot \mathrm{min}^{-1}$ (Figure 4). The reconstructivity indicates no differences in ice structure and glassy state by the cooling rate.

Crystallization of water and that of PEG occurred simultaneously with phase separation at $231 \mathrm{~K}$. However, the lowest $T$ 's at which ice formation and crystal growth of PEG were observed were different: the former was down to $200 \mathrm{~K}$, while the latter was down to $210 \mathrm{~K}$ (left in Figure 5). If the two events are completely cooperative, a difference should not be observed. This indicates that the crystallization of PEG is not a trigger for ice formation in the cooling process. This rather suggests that ice formation, which means dehydration of PEG chains, induces crystallization of PEG. This suggestion is supported by the fact that the starting $T$ of crystallization $(231 \mathrm{~K})$ is close to the homogeneous nucleation $T$ of water $(236$ K). ${ }^{56,57}$ On the other hand, the ending T's of the crystal growth of ice $(200 \mathrm{~K})$ and PEG $(210 \mathrm{~K})$ might correspond to freezing $T$ 's of their motions. The ending $T(200 \mathrm{~K})$ of the growth of ice indicates the suppression of diffusion of water molecule.

Suppression of the diffusion of water molecules in polymer matrices has been reported in several cases: polystyrene (PS, $180 \mathrm{~K}),{ }^{35,58}$ poly(methyl methacrylate) (PMMA, $\left.200 \mathrm{~K}\right),{ }^{59}$ poly $(n$-butyl methacrylate) (PBMA, $210 \mathrm{~K}),{ }^{36} \mathrm{PMEA}(210 \mathrm{~K}),{ }^{55}$ and poly(ethoxyethyl acrylate) (PEEA, $220 \mathrm{~K})^{36}$. The $T_{\mathrm{g}}$ 's of the five polymers were $373 \mathrm{~K},{ }^{60} 412 \mathrm{~K}^{61}{ }^{61} 288 \mathrm{~K}$, ${ }^{60} 223 \mathrm{~K}^{26}$ and $223 \mathrm{~K},{ }^{62}$ respectively. The relation between $T_{\mathrm{g}}$ and suppression $T$ of the diffusion clearly indicates that the suppression of diffusion depends on the strength of the electrostatic interaction site rather than $T_{\mathrm{g}}$. The suppression $T$ of diffusion of water molecules in a PEG-water system $(200 \mathrm{~K})$ is not in conflict with the tendency. Hatakeyama et al. reported on the basis of DSC that aqueous PEG solutions with $\mathrm{W}_{\mathrm{C}}$ of $19-63 \mathrm{wt} \%$ had two $T_{\mathrm{g}}$ 's of $190 \mathrm{~K}$ and $200 \mathrm{~K} .{ }^{13}$ The two $T_{\mathrm{g}}$ 's based on DSC might correspond to the freezing of motion of water molecules and PEG chains, respectively.

Recrystallization of water occurred in two steps at $198 \mathrm{~K}$ and $210 \mathrm{~K}$ (right in Figure 5). The fact that LDA-like spectra were not observed below $198 \mathrm{~K}$ clearly indicates that recrystallized water should not be generated from LDA. Recrystallized water is also thought to be generated directly from the hydration species. Such a phenomenon has been demonstrated in several water-polymer systems: PS, PBMA, PEEA, PMEA and poly(2-ethoxyethyl methacrylate). ${ }^{36,55,58}$ The spectra at 225 $\mathrm{K}$ were superposed on that of the sample cooled at $1.0 \mathrm{~K} \cdot \mathrm{min}^{-1}$. These indicate that nearly complete formation of ice and crystalline PEG was pursued and that their structures should not be different regardless of whether crystallization occurred during cooling or heating (recrystallization). However, in the two $T$ ranges of $198-210 \mathrm{~K}$ and $210-220 \mathrm{~K}$, the recrystallization process of water should not be the same because the increasing ratio of ice growth to crystal growth of PEG was different in each $T$ range.

Recrystallization of water (increase in A3250) was comparable in the two $T$ ranges of $198-210 \mathrm{~K}$ and $210-220 \mathrm{~K}$. In contrast, crystallization of PEG (increase in A2883) in the former $T$ range was much smaller than that in the latter. In the case of the sample cooled at $1.9 \mathrm{~K} \cdot \mathrm{min}^{-1}$, crystallization of PEG was negligibly small in the former $T$ range. This clearly indicates that crystallization of water in this $T$ range does not need the motion of PEG chains. This result, at the same time, 
confirms the prediction that suppression of the diffusion of water molecules occurs below $200 \mathrm{~K}$. In other word, recrystallization of water at $198 \mathrm{~K}$ occurs mainly by the re-diffusion of water molecules. The small degree of crystallization of PEG can also be explained by the prediction that PEG chains are in a glassy state below $210 \mathrm{~K}$. As stated above, the glassy state of water molecules should be achieved by the water-PEG association. In this situation, if recrystallization of water inducing dehydration of PEG chains occurs, crystallization of PEG should be small because of the restricted motion of PEG chains.

In the $T$ range of $210-220 \mathrm{~K}$, on the other hand, the PEG chain might become movable, resulting that the water molecules associated with the PEG chains also become movable. This movable water molecule might be recrystallized and then dehydration of the PEG chain with recrystallization might induce crystallization of PEG. Above 220 K, ice growth and crystal growth of PEG might be stopped due to nearly complete ice formation.

Finally, it should be discussed again why there are two cases of recrystallization of water requiring motion of PEG chains in the $T$ range of $210-220 \mathrm{~K}$ and not requiring motion of PEG chains in the $T$ range of $198-210 \mathrm{~K}$. As reiterated above, there is no doubt that the glassy state is achieved by the association between water molecules and PEG chains via $\mathrm{H}$-bonding. At the same time, there is also no doubt that helical and random PEG chains coexist in the glassy state. These two facts indicate that there are, at least, two types of water molecules binding to helical or random PEG chains. If the $T$ ranges in which the two types of water molecules can diffuse differ, the two-step recrystallization could be accepted. The question here is which hydration species could recrystallize (re-diffuse) at the lower $T$. Assuming that the water molecule bonded to the random PEG chain is recrystallized at the lower $T$, the small degree of crystallization of PEG in the $T$ range of $198-210 \mathrm{~K}$ and the subsequent large degree of it in the $T$ range of $210-220 \mathrm{~K}$ cannot be explained. The recrystallized water at the lower $T$, therefore, should be considered to be the water molecule associated with the helical PEG chain.

\section{Conclusion}

Recrystallization behavior of water in a concentrated aqueous PEG solution was investigated using $T$ variable mid-IR spectroscopy. The recrystallization process of water in this system was not essentially different from that in other non-water-soluble polymers: recrystallized water was generated from water molecules associated with polymer chains but was hardly generated from LDA. ${ }^{35,36,58,59}$ From the view point of molecular motion, it is true that water molecules in a glassy state are recrystallized, but this glassy state is achieved by the water-polymer association via electrostatic interaction (H-bonding). This suggests that the recrystallizable water should not have a specific H-bonding structure. The notable difference between the PEG-water system and others was that two-step recrystallization of water occurred. This is due to the coexistence of two types of polymer configurations, 7/2 helical and random PEG chains. In other words, two types of water molecules binding to the helical and random chains exist and their recrystallization T's are different. This is direct evidence that the recrystallized water hardly has a specific H-bonding structure.

Acknowledgements. This work was supported by a Grant-in-Aid for Young Scientist (No. 24750216) and for Scientific Research (No. 22350101) from JSPS and a Grant-in-Aid for Scientific Research on Innovation Areas (No. 20106007) from MEXT.

Supporting Information Available: $T$ dependence of spectra of the PEG solution at intermediate cooling rates. This material is available free of charge via the Internet at http://pubs.acs.org.

\section{References}

1) Okano, T.; Nishiyama, S.; Shinohara, I.; Akaike, T.; Sakurai, Y.; Kataoka, K.; Tsuruta, T. J. Biomed. Mater. Res. 1981, $15,393$.

2) Stevens, M. M.; Gerge, J. H. Science 2005, 310, 1135.

3) Discher, D. E.; Mooney, D. J.; Zandstra, P. W. Science 2009, 324, 1673.

4) Mitragotri, S.; Lahann, J. Nat. Mater. 2009, 8, 457.

5) Lee, J. H.; Li, T.; Park, K. In Water in Biomaterials Surface Science; Morra, M., Ed.; Wiley: Chichester, 2001, p.307-332.

6) Lu, D. R.; Lee, S. J.; Park, K. J. Biomat. Sci. Polym. Ed. 1991, 3, 127.

7) Tsuruta, T. J. Biomater. Sci. Polym., Ed. 2010, 21, 1831.

8) Harris, J. M.; Zalipsky, S. Poly(ethylene glycol): Chemistry and Biological Application; American Chemical Society: Washington, D. C., 1997.

9) Graham, N. B.; Zulfigar, M.; Nwachuku, N. E.; Rashid, A. Polymer 1989, 30, 528.

10) Huang, L.; Nishinari, K. J. Polym. Sci. B-Polym. Phys. 2001, 39, 496.

11) Trotzig, C.; Abrahmsén-Alami, S.; Maurer, F. H. J. Polymer 2007, 48, 3294.

12) Lai, W.-C. Liau, W-.B. Lin, T-.T. Polymer 2004, 45, 3073.

13) Hatakeyama, T.; Kasuga, H.; Tanaka, M.; Hatakeyama, H. Thermochim. Acta 2007, 465, 59.

14) Takei, T.; Sugitani, Y. Anal. Sci. 2010, 26, 337.

15) Pochylski, M.; Gapliński, J. J. Phys. Chem. B, 2010, 114, 2644. 
16) Morra, M. In Water in Biomaterials Surface Science; Morra, M., Ed.; Wiley: Chichester, 2001, p.307-332.

17) Zolk, M.; Eisert, F.; Pipper, J.; Herrwerth, S.; Eck, W.; Buck, M.; Grunze, M. Langmuir 2000, $16,5849$.

18) Harder, P.; Grunze, M.; Dahint, R.; Whitesides, G. M.; Laibinis, P. E. J. Phys. Chem. B 1998, $102,426$.

19) Pale-Grosdemange, C.; Simon, E. S.; Prime, K. L.; Whitesides, G. M. J. Am. Chem. Soc. 1991, 113, 12.

20) Feldman, K.; Hahner, G.; Spencer, N. D.; Harder, P.; Grunze, M. J. Am. Chem. Soc. 1999, 121, 10134.

21) Wang, R. L. C.; Kreuzer, H. J.; Grunze, M. J. Phys. Chem. B 1997, 101, 9796.

22) Prime, K. L.; Whitesides, G. M. J. Am. Chem. Soc. 1993, 115, 10714.

23) Jiang, X.; Ferrigno, R.; Mrksich, M.; Whitesides, G. M. J. Am. Chem. Soc. 2003, 125, 2366.

24) Ostuni, E.; Grzybowski, B. A. Mrksich, M.; Roberts, C. S.; Whitesides, G. M. Langmuir 2003, $19,1861$.

25) Sigal, G. B.; Mrksich, M.; Whitesides, G. M. J. Am. Chem. Soc. 1998, 120, 3464.

26) Tanaka, M.; Motomura, T.; Kawada, M.; Anzai, T.; Kasori, Y.; Shiroya, T.; Shimura, K.; Onishi, M.; Mochizuki, A. Biomaterials 2000, 21, 1471 .

27) Tanaka, M.; Motomura, T.; Ishii, N.; Shimura, K.; Onishi, M.; Mochizuki, A.; Hatakeyama, T. Polym. Int. 2000, 49, 1709.

28) Furushima, Y.; Ishikiriyama, K.; Ueno, Y.; Sugaya, H. Thermochim. Acta 2012, 538, 43.

29) Hatakeyama, T.; Naoi, S.; Hatakeyama, H. J. Therm. Anal. Calorim. 2002, 70, 841.

30) Yoshida, H.; Hatakeyama, T.; Hatakeyama, H. Polymer 1990, 31, 693.

31) Hatakeyama, T.; Yoshida, H.; Hatakeyama, H. Polymer 1987, 28, 1282.

32) Hatakeyama, T.; Tanaka, M.; Hatakeyama, H. Acta Biomater. 2010, 6, 2077.

33) Shi, D.; Zhang, X.; Dong, W.; Chen, M. Polym. Sci. B 2012, 54, 335.

34) Tanaka, M.; Mochizuki, A. J. Biomed. Mater. Res. 2004, 68A, 684.

35) Gemmei-Ide, M.; Hiromi, K. J. Phys. Chem. B 2008, 112, 13499.

36) Gemmei-Ide, M.; Ohya, A.; Kitano, H. J. Phys. Chem. B 2012, 116, 1850.

37) Ide, M.; Yoshikawa, D.; Maeda, Y.; Kitano, H. Langmuir 1999, 15, 926.

38) Kitano, H.; Ichikawa, K.; Ide, M.; Fukuda, M.; Mizuno, W. Langmuir 2001, 17, 1889.

39) Gemmei-Ide, M.; Motonaga, T.; Kitano, H. Langmuir 2006, 22, 2422.

40) Miyazawa, T.; Fukushima, K.; Ideguchi, Y. J. Chem. Phys. 1962, 37, 2764.

41) Yoshihara, T.; Tadokoro, H.; Murahashi, S. J. Chem. Phys. 1964, 41, 2902.

42) Hager, S. L.; MacRury, T. B. J. Appl. Polym. Sci. 1980, 25, 1559.

43) de Vringer, T.; Joosten, J. G.; Junginger, H. E. Colloid Polym. Sci. 1986, 264, 623.

44) Tilcock, C. P. S.; Fisher, D. Biochim. Biophys. Acta 1982, 688, 645.

45) Kjellander, R.; Florin, E. J. Chem. Soc. Faraday Trans. 1981, 177, 2053.

46) Maxfield, J.; Shepherd, I. W. Polymer 1975, 16, 505.

47) Güveli, D. E.; Davis, S. S.; Kayes, J. B. J. Colloid Interf. Sci. 1983, 91, 1.

48) Washbum, E. W. In International Critical Tables of Numerical Data, Physics, Chemistry and Technology; McGraw-Hill: New York, 1929; Vol. 5, pp131-138.

49) Mallamace, F.; Broccio, M.; Corsaro, C.; Faraone, A.; Majolino, D.; Venuti, V.; Liu, L.; Mou, C.-Y.; Chen, S.-H. Proc. Natl. Acad. Sci. USA 2007, 104, 4247.

50) Bergren, M. S.; Schuh, D.; Sceats, M. G.; Rice, S. A. J. Chem. Phys. 1978, 68, 3477.

51) Cwilong, B. M. Proc. R. Soc. London 1947, A190, 137.

52) Schaefer, V. J. Ind. Eng. Chem. 1950, 44, 1300.

53) Bigg, E. K. Q. J. R. Meteorol. Soc. 1953, 79, 510.

54) Clausse, D.; Dumas, J. P.; Broto, F. C. R. Acad. Sci. 1974, $279 B, 415$.

55) Gemmei-Ide, M. and Kitano, H. J. Phys. Chem. B 2008, 112, 12863.

56) Hobbs, P. V. In Ice Physics; Clarendon Press: Oxford, U.K., 1974, pp 461-523.

57) Angell, C. A. In Water: A Comprehensive Treatise; Franks, F., Ed.; Plenum Press: New York, 1982; Vol. 7, pp 1-81.

58) Gemmei-Ide, M.; Kitano, H. J. Phys. Chem. B 2008, 112, 2764.

59) Gemmei-Ide, M.; Motonaga, T.; Kitano, H. J. Phys. Chem. B 2007, 111, 5533.

60) Guschl, P.; Otaigbe, J. U. J. Colloid Interface Sci. 2003, 266, 82.

61) Nikitin, L. N.; Said-Galiyev, E. E.; Vinokur, R. A. Khokhlov, A. R.; Gallyamov, M. O.; Schaumburg, K. Macromolecules 2002, 35, 934.

62) Bovey, F. A.; Abere, J. F. J. Polym. Sci. 1955, 15, 537. 

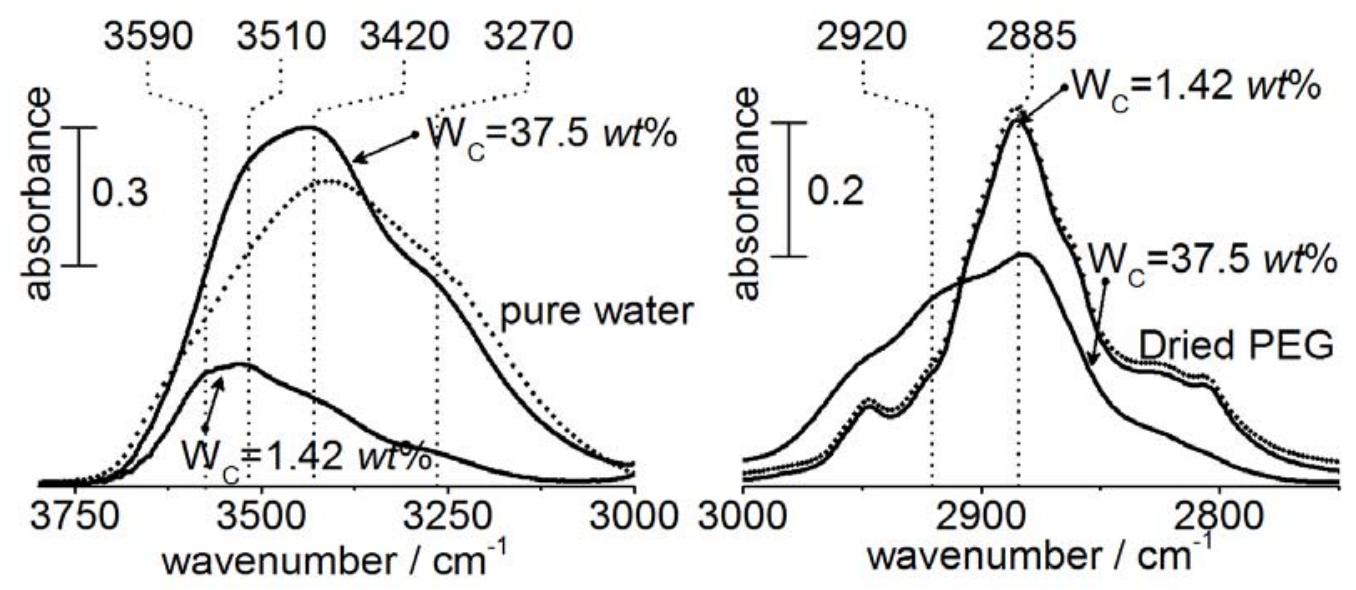

Figure 1. M. Gemmei-Ide et al. 


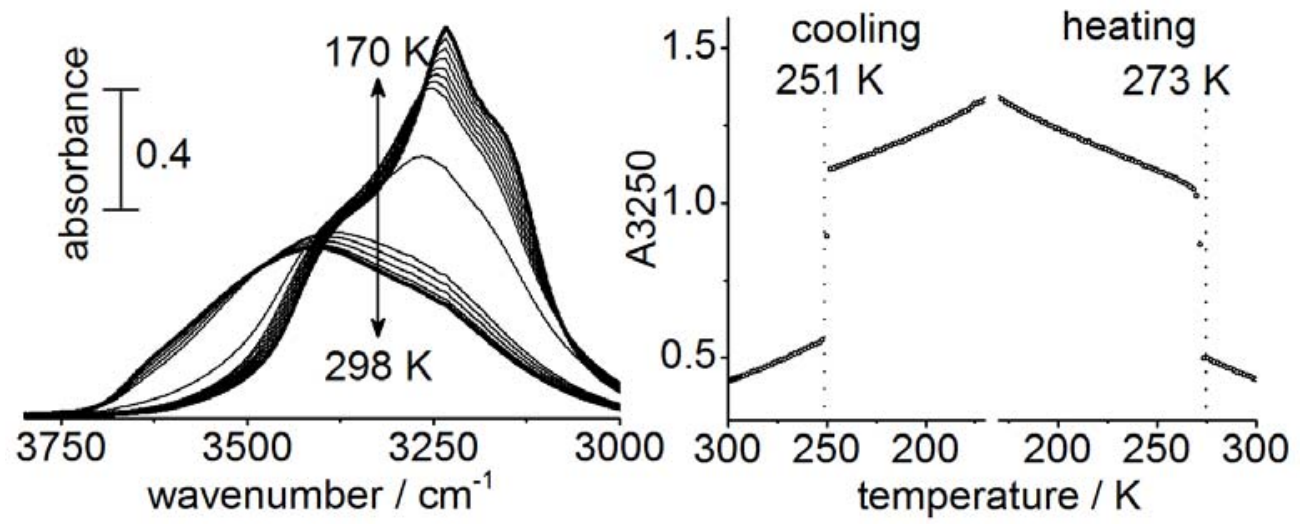

Figure 2. M. Gemmei-Ide et al. 
(a) liquid water ice $I_{\mathrm{h}}$ LDA
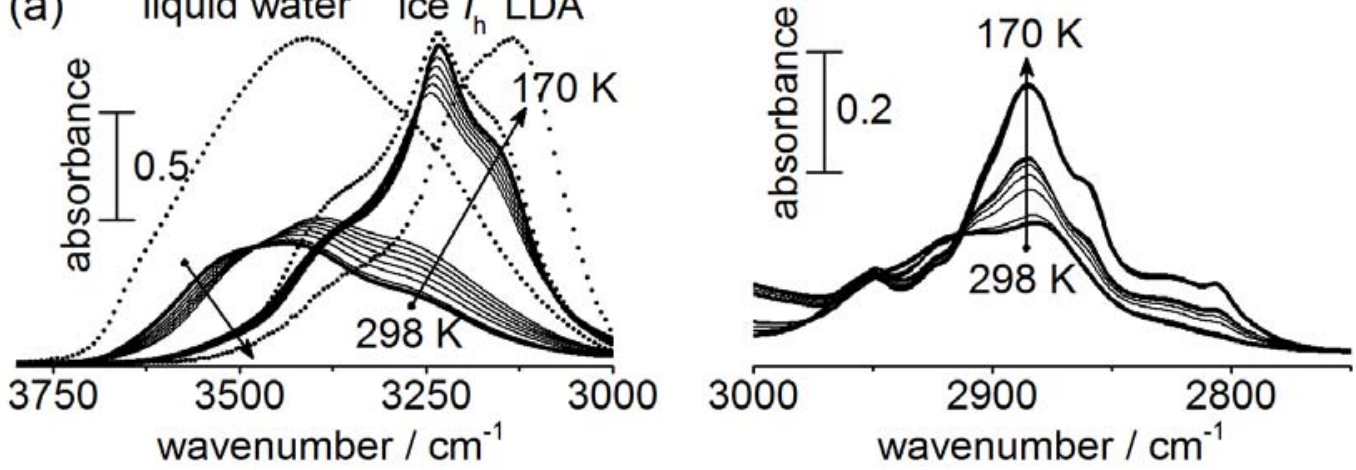

(b)
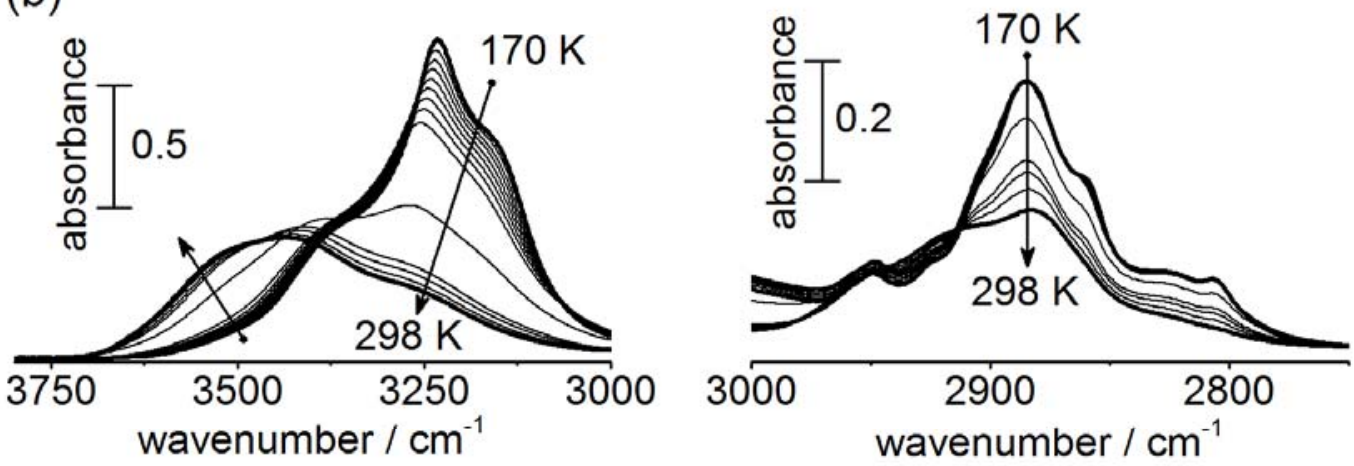

(c)

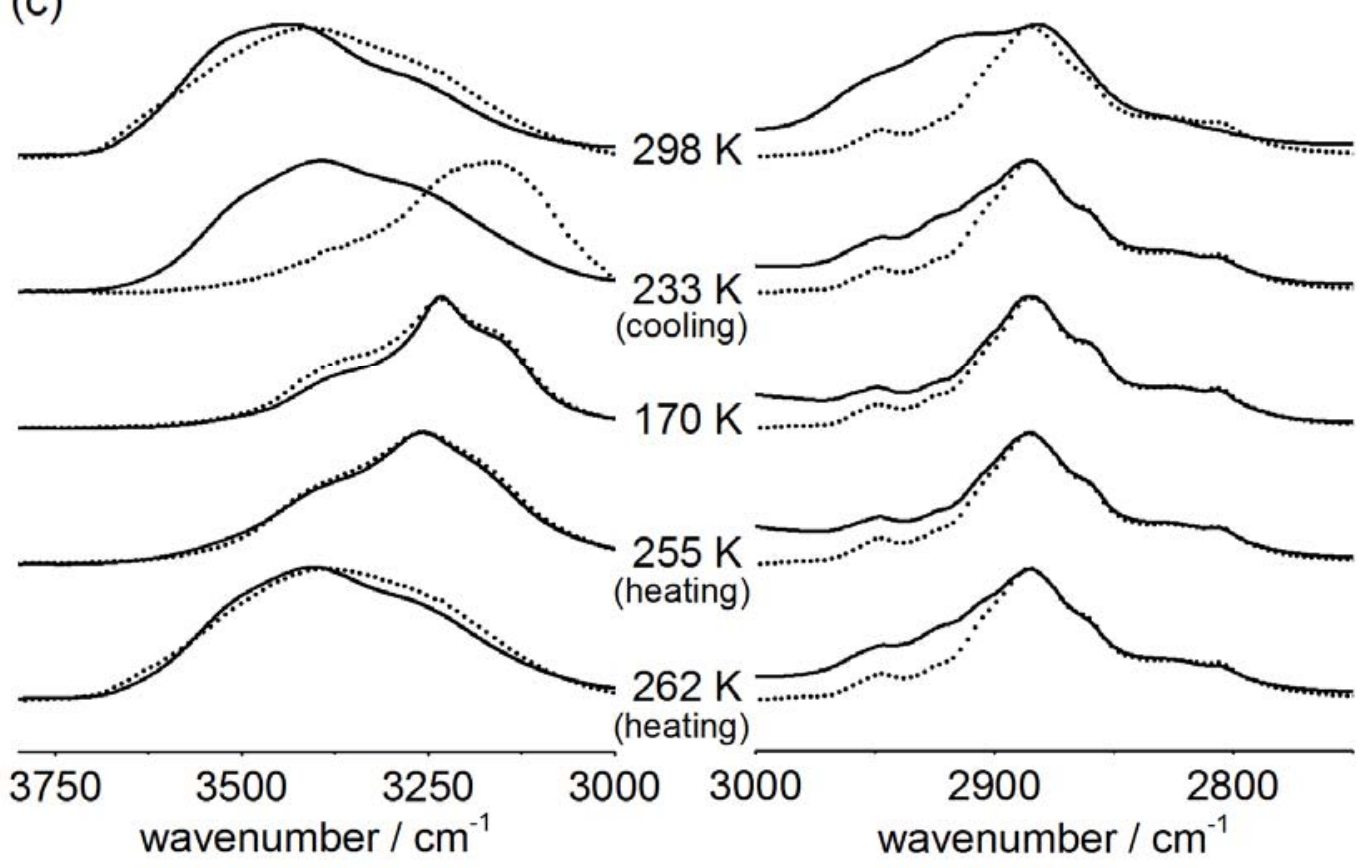

Figure 3. M. Gemmei-Ide et al. 

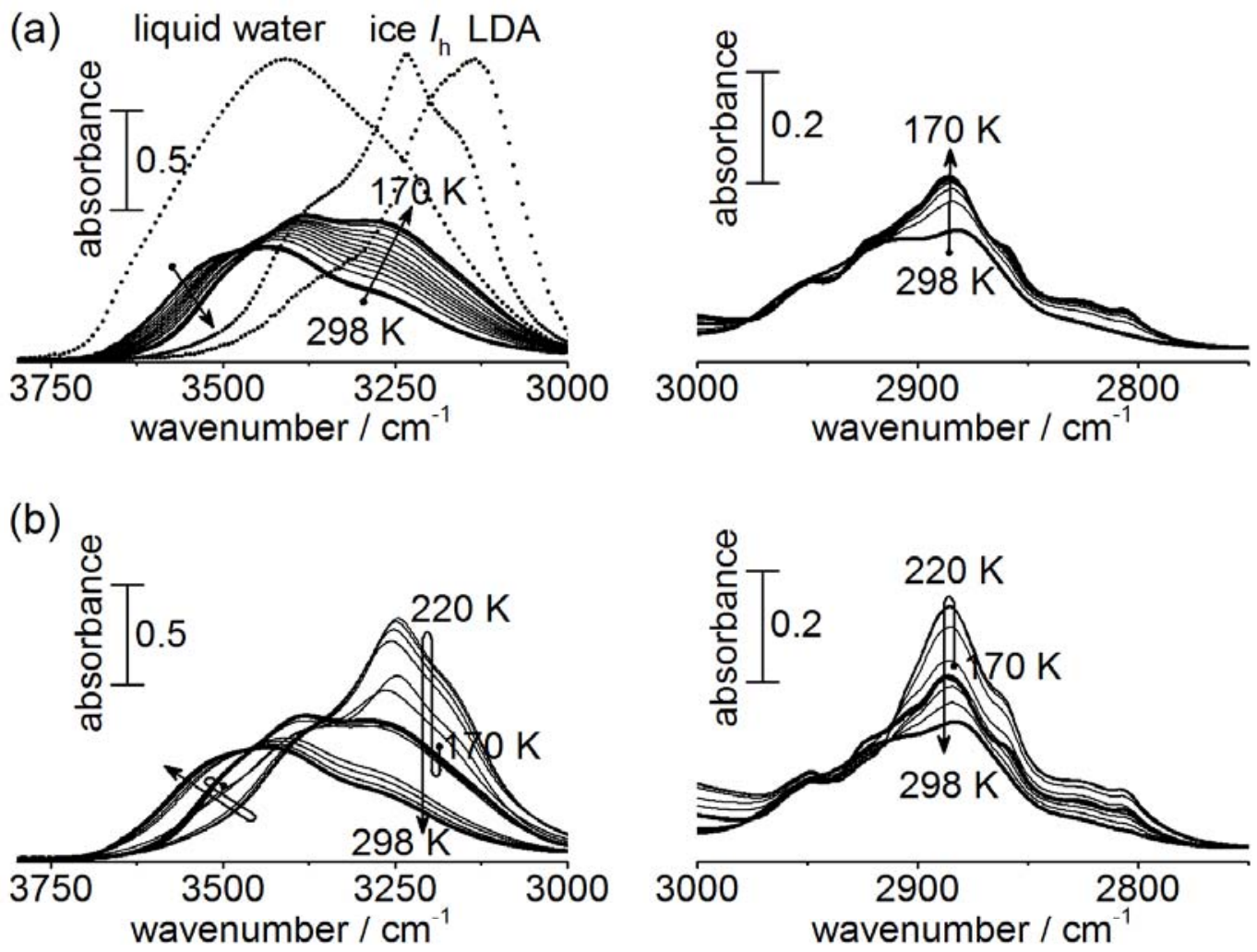

(c)

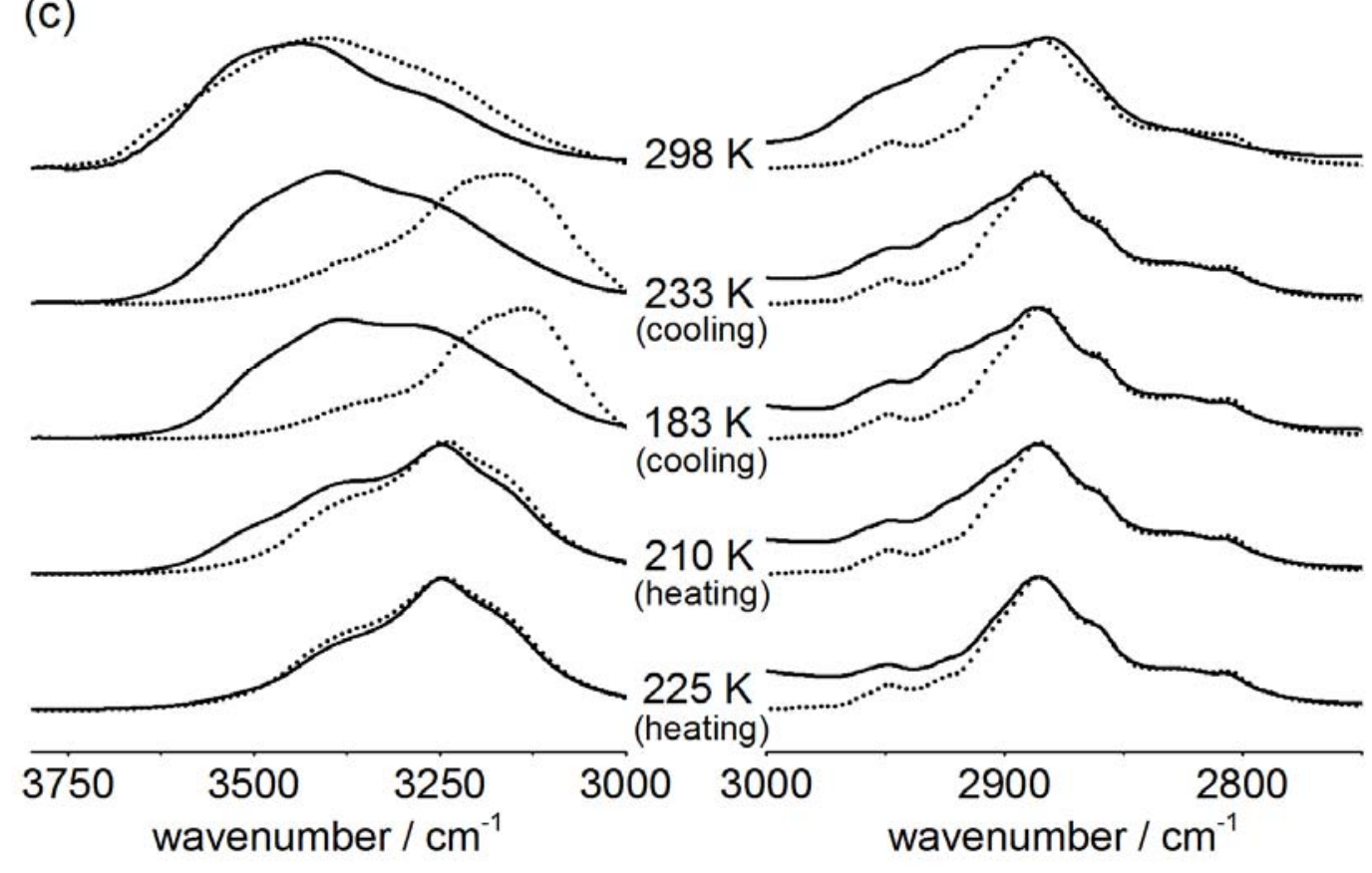

Figure 4. M. Gemmei-Ide et al. 


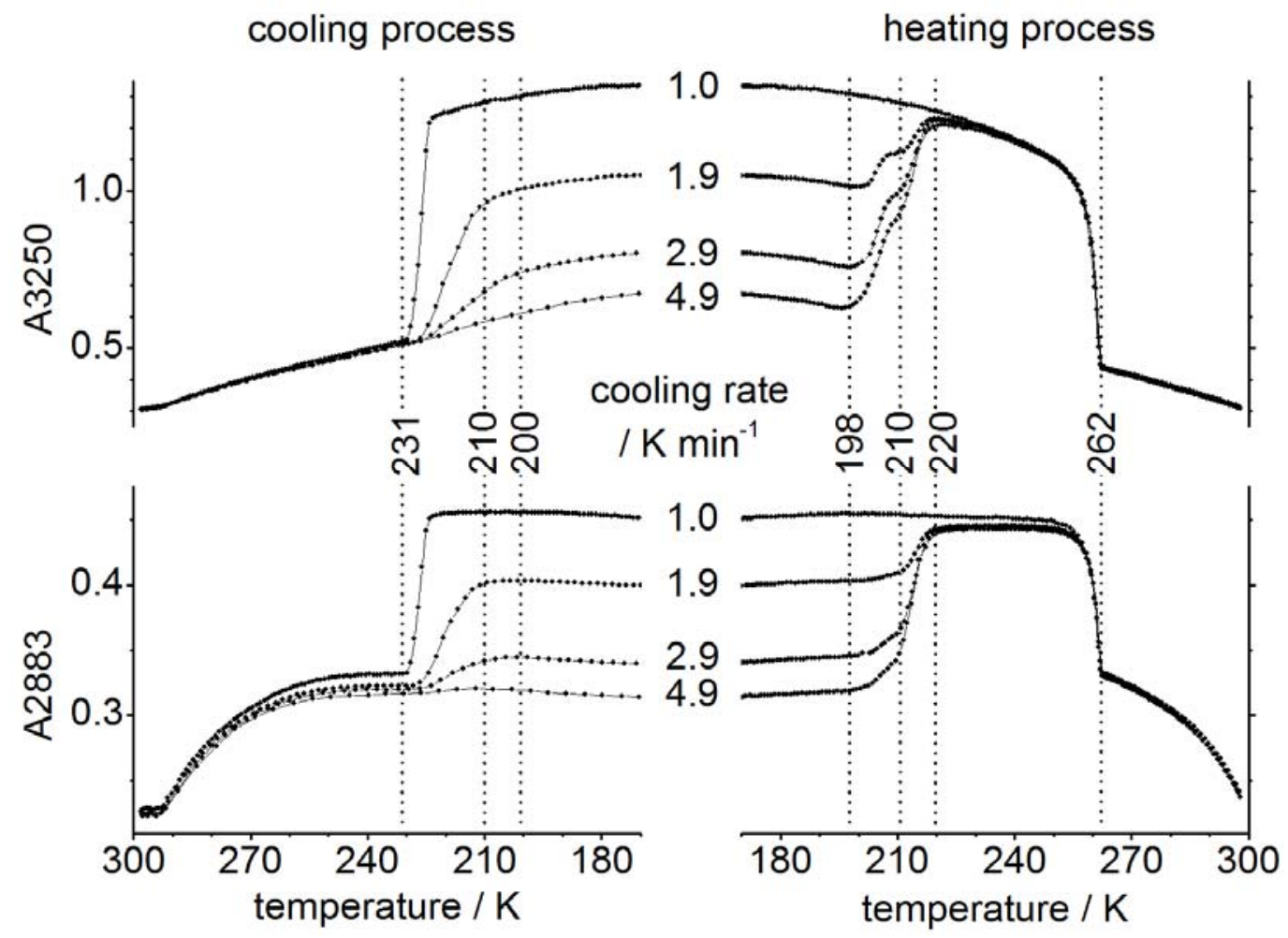

Figure 5. M. Gemmei-Ide et al. 
Recrystallization of Water

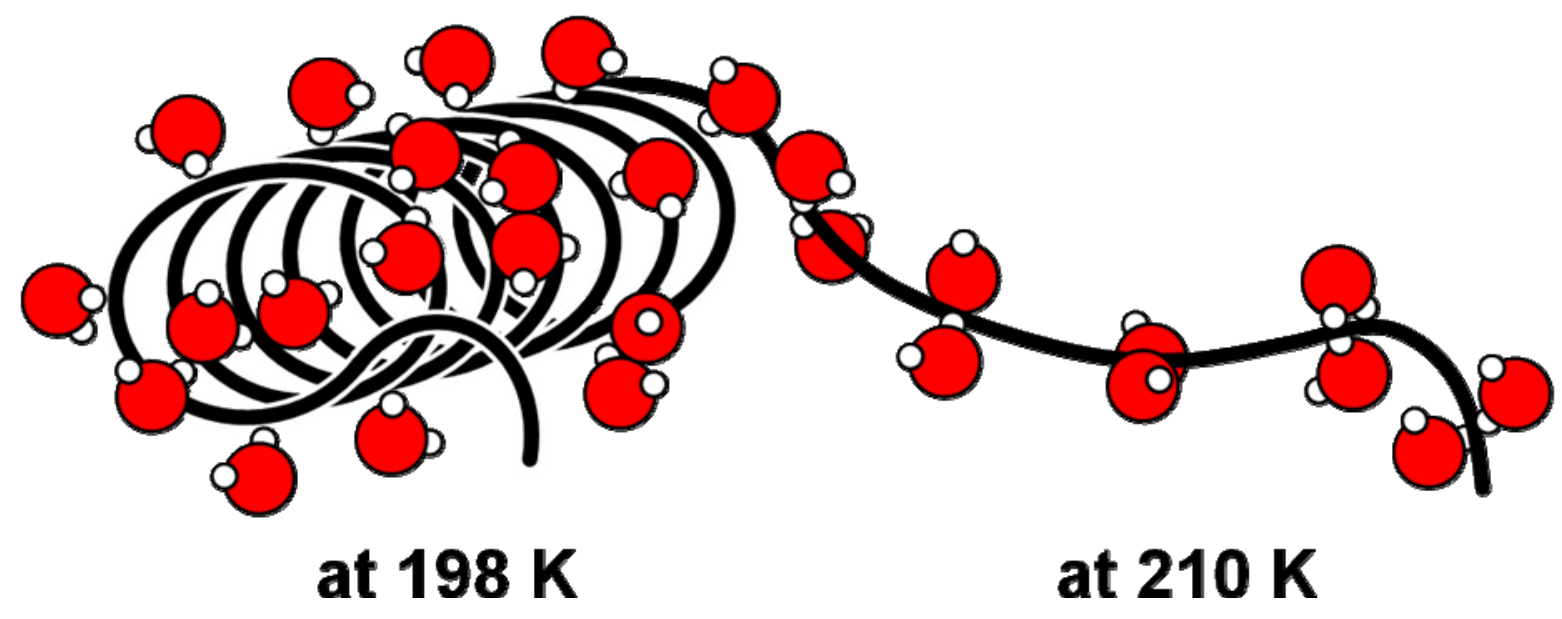

